\title{
UNIDADES DE MAPEAMENTO DE SOLOS SOB CULTIVO DE CANA-DE-AÇÚCAR EM 2011: ANÁLISE DA EXPANSÃO DA CULTURA NO SUDOESTE DE GOIÁS (BRASIL)
}

\author{
Íria Oliveira Franco ${ }^{1}$ \\ Iraci Scopel ${ }^{2}$ \\ Hildeu Ferreira Assunção ${ }^{3}$
}

RESUMO: Esperava-se que a atividade canavieira no Sudoeste de Goiás (SW-GO) ocorresse em solols marginalizados ao cultivo de grãos. Entretanto, observou-se que isto não foi o que aconteceu, pois, o plantio e a expansão da cana-de-açúcar ocorreram em solos com aptidão agrícola regular e boa para lavouras anuais. Neste trabalho identificou-se as unidades de mapeamento de solos mais utilizadas com o cultivo de cana no SW-GO, no ano de 2011. A partir da classificação das áreas com cana nas imagens de satélite, em 2011, e apoio de campo, foi feita a sobreposição no mapa temático de solos, compilado da base de dados do Sistema de Informações Geográficas do Estado de Goiás de 2006. Assim, a área cultivada com cana no SW-GO, em 2011, foi de 242.988 ha, equivalente a 33,2 \% da área cultivada com cana no Estado (INPE/Canasat, 2012), no ano-safra de 2011/2012. Das unidades de mapeamento de solos, a mais utilizada com cana no ano de 2011 foi a dos Latossolos com 186.811 ha. Os Neossolos Quartzarênicos apresentaram uma área cultivada com cana de apenas 30.256 ha, correspondente a 12,4 \% das áreas de cana no SW-GO, no ano de $2011 / 2012$.

Palavras-chave: aptidão agrícola dos solos; uso e cobertura do solo; cana-de-açúcar; Goiás.

\section{SOIL MAPPING UNITS UNDER SUGAR CANE GROWING IN THE YEAR OF 2011 IN SOUTHWEST OF GOIÁS STATE, BRAZIL}

ABSTRACT: It was hoped that the sugarcane growing in the southwest of Goiás state, Brazil (SW-GO-BR), took place in land inappropriate for grain crops. However, it was observed that this not happened in the expansion of sugarcane, because this occurred preferentially in soils with good and regular agricultural suitability for annual crops. The objective of this study was to identify the soil-mapping units commonly used with sugarcane in the SW-GO-BR, in 2011. From the classification of satellite images areas with sugarcane, in 2011, supported by fieldwork, the overlap was did upper soil map, this compiled from the database of the Geographic Information System of Goiás State of the 2006 year. The results indicated that the area cultivated with sugarcane in SW-GO-BR, in 2011, was of 242.988 ha, equivalent to $33,2 \%$ of the area cultivated with sugarcane throughout the State (INPE/Canasat, 2012), in the harvest crop year 2011/2012. Of the soil mapping units, the most widely used with sugarcane, in 2011, was the Oxisols with 186811 ha. The Quartzipsamment soils showed an area cultivated with sugarcane of 30.256 ha, representing $12,4 \%$ of the cane areas in the SW-GO-BR, in harvest year of 2011/2012

Keywords: agricultural suitability of land; use and land cover; sugar cane; Goiás

1. Universidade Federal de Goiás, Campus de Jataí - Goiás (iria biologa@ymail.com).

2. Universidade Federal de Goiás, Campus de Jataí - Goiás (iraciscopel@gmail.com).

3. Universidade Federal de Goiás, Campus de Jataí - Goiás (hildeu@yahoo.com.br). 


\section{INTRODUÇÃO}

O conhecimento edáfico é muito importante para avaliar a capacidade produtiva dos solos (LEPSCH, 1987). A cana-de-açúcar é cultivada em quase todas as classes de solos, algumas vezes, naqueles com características muito aquém das idealmente desejáveis (KOFFLER, DONZELLI, 1987; DEMATTÊ, 2004).

No final da década de 1970 e no início dos anos de 1980, os solos cultivados, predominantemente, com cana-de-açúcar nos principais Estados produtores do Brasil eram: a) Latossolos com cerca de 67 \%, em São Paulo; b) Latossolos e Argissolos, com 49 e 32 \%, respectivamente, em Pernambuco; c) Argissolos e Latossolos, respectivamente, com 55 e 35 $\%$, em Alagoas e d) Associação de Latossolos + Argissolos, Gleissolos e outros, com 53 e 38 $\%$, respectivamente, no Rio de Janeiro (RIZZO e ORLANDO, 1980).

Atualmente, as principais ordens de solos cultivados com cana-de-açúcar, especialmente na região Centro Sul do Brasil, são: Latossolos, Nitossolos, Argissolos e, as demais ordens, com pouca expressão em área, como a dos Neossolos Quartzarênicos, por exemplo. Na região nordestina, predomina a ocupação dos Latossolos Vermelho-Amarelos, dos Latossolos Amarelos e dos Argissolos (DEMATTÊ, 2004).

Cada um desses solos apresenta potencial de produção específica para a cana, porém, este potencial produtivo/econômico está associado, também, às características do local (FRANCO, 2012), como ao clima, à topografia, à logística, as quais contribuem para estabelecer os níveis de rendimento da cultura.

Quanto à expansão da cana em Goiás, Castro, Borges e Amaral (2008), analisando a topografia, os solos e o potencial de ocupação com a cultura, concluíram que cerca de $60 \%$ das áreas do Estado de Goiás apresentam solos com moderada a elevada aptidão agrícola para a cultura da cana, comportando, principalmente, os Latossolos, os Argissolos e os Cambissolos.

Ainda que seja possível encontrar áreas plantadas com cana-de-açúcar em quase todas as classes dos solos de Goiás, se não forem consideradas as Unidades de Conservação e as Áreas Prioritárias para Conservação, 77 \% da cana plantada no Estado, no ano de 2007, encontrava-se em Latossolos e $97 \%$, sob relevo plano a suave ondulado, com declividade até $6^{\circ}$, portanto, nas áreas favoráveis à mecanização (RIBEIRO, 2010).

Portanto, pretendeu-se fazer um levantamento de modo a identificar e quantificar as unidades de mapeamento de solos utilizadas para o cultivo de cana-de-açúcar no sudoeste de Goiás, no ano de 2011, usando técnicas de sensoriamento remoto e apoio/levantamentos a campo.

\section{MATERIAL E MÉTODO}

Para a identificação das áreas de cultivo de cana-de-açúcar no SW de Goiás foram tratadas e analisadas imagens orbitais, composições coloridas RGB do Landsat 5, ano base de 2011, compostas pelas bandas 3, 4 e 5 do sensor TM, cujas órbitas/pontos correspondem a: 22272, 222-73, 223-71, 222-72, 222-73, 224-71, 224-72 e 224-73. Os softwares para interpretação das imagens e georreferenciamento utilizados foram o ERDAS Imagine 8.6, e o ArcGis 9.3. 
O software ERDAS Imagine 8.6, utilizado para a interpretação das imagens, apresenta a seguinte sequência (rotina): 1) agrupamento de imagens, gerando, neste caso, a composição colorida 3R 4G 5B; 2) ortorretificação, onde foram utilizadas, também, imagens do Landsat 7 de 2002 e cartas topográficas do IBGE, na escala 1:100.000, com pontos de controle, sendo re-projetadas para o Geographic Coordinate System, Datum SAD 69, zona 22 Sul; 3) classificação não supervisionada, onde foram criadas 100 classes. A classificação foi feita utilizando-se pontos de aferição a campo; 4) agrupamento de pixels com classes de níveis de cinza pré-definidos, reduzindo-se a oito classes de cobertura de solo.

As áreas de agricultura foram analisadas, separadamente, no software ArcGis 9.3 e, posteriormente, incorporadas à classificação, obtendo-se assim as seguintes classes: a) Mata: floresta seca, floresta úmida e cerradão; b) Cerrado: cerrado, campo cerrado; c) Campo: campo sujo, campo úmido, campo limpo e campo rupestre; d) Corpo d'água: rios, córregos, lagos e lagoas; e) Pastagem: em diversas situações; f) Cana-de-açúcar; g) Agricultura: soja, milho, algodão e outros; h) Não classificada: sombra de encostas, nuvens e áreas de difícil identificação.

Ainda, utilizando-se o software ERDAS Imagine 8.6, após a classificação, a imagem foi filtrada através do método do "Nearest Neighborhood", (vizinho mais próximo), na malha de $3 \times 3$ pixels, eliminando-se os pixels com valores incoerentes e dispersos nas classes consideradas. $\mathrm{Na}$ sequência, o arquivo, em formato Raster, foi transformado em formato Vetorial e calcularam-se os perímetros e áreas das classes em hectares.

A partir da classificação das áreas de cana-de-açúcar de 2011, foi feito o cruzamento com o mapa de solos, cuja fonte foi a base de dados do Sitema Estadual de Geoinformação de Goiás (SIEG, 2006), identificando-se as unidades de mapeamento de solos cultivadas com cana-de-açúcar no SW de Goiás no ano de 2011.

Finalmente, devido a fatores técnicos, como ocorrência parcial de nuvens em algumas imagens, resposta espectral das diferentes coberturas do solo - dadas às fases de desenvolvimento da cultura, como plantio, colheita, restos culturais e queima da palha -, considerou-se, após checagem a campo dos dados da classificação, uma variação na quantificação, das áreas das Unidades de mapeamento, em torno de $5 \%$.

\section{DESCRIÇÃO DA ÁREA DE ESTUDO}

A microrregião Sudoeste (SW) do Estado de Goiás (Figura 01) está localizada entre os paralelos $16^{\circ} 27^{\prime}$ e $19^{\circ} 15^{\prime} \mathrm{S}$ e entre os meridianos $53^{\circ} 12^{\prime}$ e $50^{\circ} 12^{\prime} \mathrm{W}$; é constituída pelos municípios de Aparecida do Rio Doce, Aporé, Caiapônia, Chapadão do Céu, Castelândia, Doverlândia, Jataí, Maurilândia, Mineiros, Montividiu, Palestina de Goiás, Perolândia, Portelândia, Rio Verde, Santa Helena de Goiás, Santa Rita do Araguaia, Santo Antônio da Barra e Serranópolis, totalizando $49.264 \mathrm{~km}^{2}$, correspondentes a 14,5\% da área estadual (IBGE, 2012). 


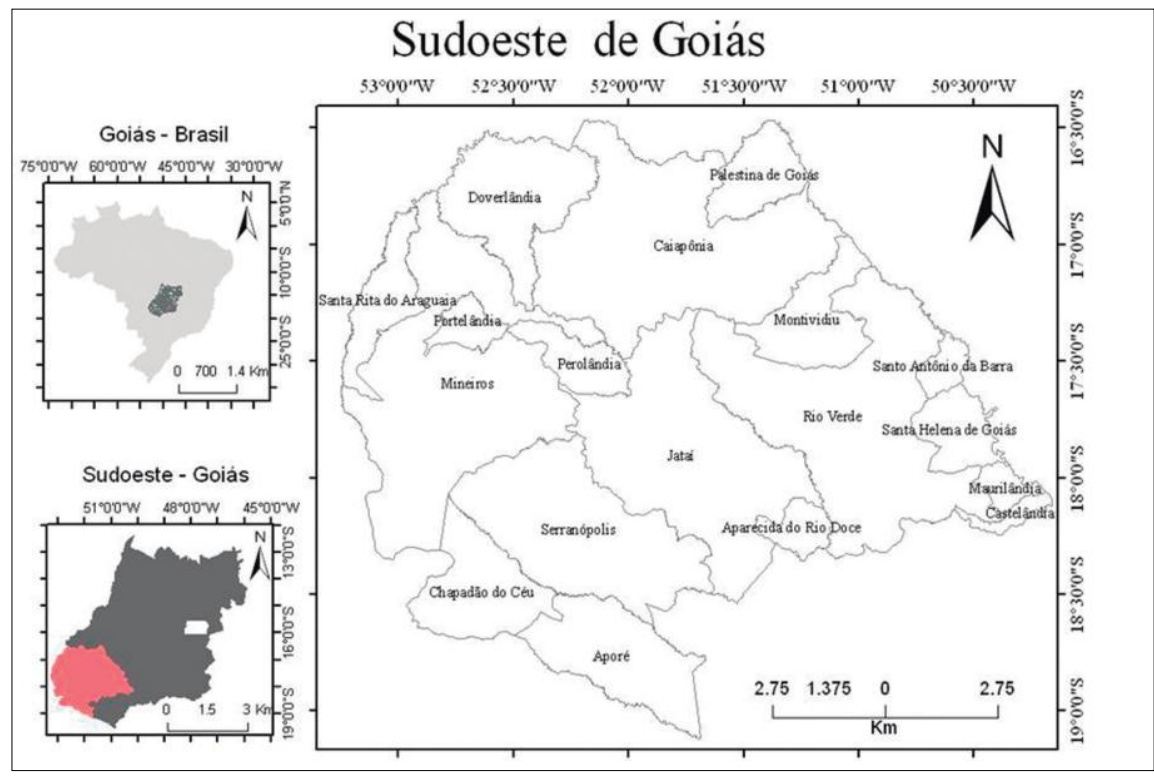

FIGURA 01: Localização da área de estudo.

Fonte: SIEG (2006).

- Clima: O SW-GO possui clima tropical de savana, classificado como Aw por Köppen, com período chuvoso de outubro a abril e seco de maio a setembro. A temperatura média anual oscila entre $21^{\circ}$ e $23^{\circ} \mathrm{C}$ e a média anual pluviométrica é de cerca de 1700 mm (SCOPEL et al., 1995).

- Vegetação: A cobertura vegetal dominante no SW-GO é de Cerrado, composto, predominantemente, por formações savânicas, que ocupam cerca de 70 \% dos mais de 2 milhões de $\mathrm{km}^{2}$ da área caracterizada como Cerrado. Dentro deste bioma, as fitofisionomias incluem formações florestais, com a predominância de espécies arbóreas, formações campestres, em que o estrato herbáceo e arbustivo é predominante e as formações savânicas, compostas por arbustos com troncos tortuosos e árvores dispersas sobre um estrato gramíneo (RIBEIRO e WALTER, 2008). Esta diversidade vegetal é determinada pelo tipo de solo, clima e irregularidades do regime pluviométrico, especificidade das queimadas que ocorrem - periodicidade, época, intensidade - e pela atuação humana, a qual se reflete nas maiores modificações da vegetação do Cerrado (COUTINHO, 2000).

O principal fator que está determinando a redução de áreas de Cerrado é o uso agrícola. Assim, por exemplo, a produção agropecuária determinou, entre 2006 e 2007, o desaparecimento de $2.860 \mathrm{~km}^{2}$ de Cerrado e, dentre os municípios do SWGO, Caiapônia, Chapadão do Céu, Mineiros e Santa Rita do Araguaia foram os que apresentaram as maiores áreas desmatadas nos anos de 2003 a 2007 (FERNANDES et al., 2009, apud MALHEIROS e HANAI, 2010). Entretanto, o maior desmatamento, na maioria dos municípios, ocorreu nos anos anteriores à década de 1970, com a exploração pecuária. Em geral, o cultivo de grãos no SW-GO ocorreu a partir de meados da década de 1970, sobre áreas antes devotadas à pecuária.

Com a expansão da ocupação agrícola no Cerrado - a partir da década de 1970 - com os grãos, e com o aumento na demanda por biocombustíveis, é difícil negar o conflito entre o uso/ocupação para a produção de alimentos e para a produção de energia. Assim, acredita-se que o Cerrado continuará sendo desmatado - apesar do pouco 
que ainda existe - comprometendo ainda mais as reservas remanescentes em biodiversidade e a qualidade ambiental.

- Solos: O SW-GO apresenta extensos chapadões, com substrato de arenitos, basaltos e sedimentos detríticos lateríticos, cujos solos, em grande parte, são resultantes do intemperismo desses materiais geológicos. ${ }^{4}$ Em geral, nos chapadões e interflúvios encontra-se a Unidade de Mapeamento: Associação Latossolo Vermelho Aluminoférrico+Latossolo Vermelho Distroférrico. Nos vales, nas planícies aluviais e nas encostas ocorrem Unidades de Mapeamento constituídas por Argissolos, Gleissolos, Cambissolos, Neossolos Litólicos, e outros, com menor expressão espacial ou Associações desses solos. Os Neossolos Quartzarênicos, ordem de interesse especial neste trabalho, ocorrem em variadas situações de relevo, sempre derivados de materiais de origem areníticos (GUERRA et al., 1989).

Segundo Lopes (1984) e Macedo (1996), as principais classes de solos do Cerrado em Goiás, ao nível de ordem, são os Latossolos, que ocupam $48,8 \%$, os Neossolos Quartzarênicos, com 15,2 \%, os Argissolos, com 15,1 \%, os Neossolos Litólicos, com 7,3 \%, os Plintossolos, com $6 \%$, os Cambissolos, com $3 \%$, os Plintossolos Pétricos concrecionários, com 2,8 \%, os Gleissolos, com $2 \%$ e os Nitossolos, com 1,7 \%. Em trabalho realizado por Scopel et al. (2011), a área de Neossolos Quartzarênicos (RQ), especificamente, no SW de Goiás foi estimada em mais de $20 \%$, considerando-se como fazendo parte dessa classe os Latossolos de textura arenosa, muito semelhantes em comportamento aos RQ.

\section{RESULTADOS E DISCUSSÃO}

As principais Unidades de Mapeamento encontradas foram as de: Latossolos, que representam 45,9 \%; Neossolos Quartzarênicos (RQ), com 10 \%; Cambissolos, com 9,7 \%; Gleissolos Melânicos e Argissolos, que representam juntas 18,2 \%. O valor subestimado dos $\mathrm{RQ}$ deveu-se, em parte, à não computação de sua presença nas Associações de solos nas quais o nome dado à Unidade, muitas vezes, privilegia apenas o componente principal e os componentes da Associação, não nomeando as Inclusões de solos. As unidades de mapeamento de solos do SW de Goiás estão representadas na Tabela 01 e na Figura 02.

4. Os nomes das classes de solos citadas foram atualizadas pelos autores deste trabalho, utilizando a nomenclatura de solos da EMBRAPA (2006). 
TABELA 01: Unidades de mapeamento de solos identificadas no sudoeste de Goiás, com suas respectivas extensões, conforme a nova classificação de solos da EMBRAPA (2009).

\begin{tabular}{lrr}
\hline CLASSES DE SOLOS & ÁREA $\left(\mathrm{KM}^{2}\right)$ & ÁREA (\%) \\
\hline Neossolos Quartzarênicos - RQ & $4.695,6$ & 10,0 \\
Argissolos Vermelhos - PV & $4.279,0$ & 9,1 \\
Cambissolos Háplicos - CX & $4.551,1$ & 9,7 \\
Gleissolos Melânicos - GM & $4.259,5$ & 9,1 \\
Latossolos Vermelho-Amarelos - LVA & $3.680,9$ & 7,9 \\
Latossolos Vermelhos - LV & $11.799,4$ & 25,2 \\
Latossolos Vermelhos Distroférricos - LVd & $5.999,6$ & 12,8 \\
Neossolos Regolíticos - RR & $3.935,2$ & 8,4 \\
Nitossolos Vermelhos Eutróficos - NVe & $3.672,7$ & 7,8 \\
\hline
\end{tabular}

Fonte: SIEG (2006); RADAMBRASIL (1983).

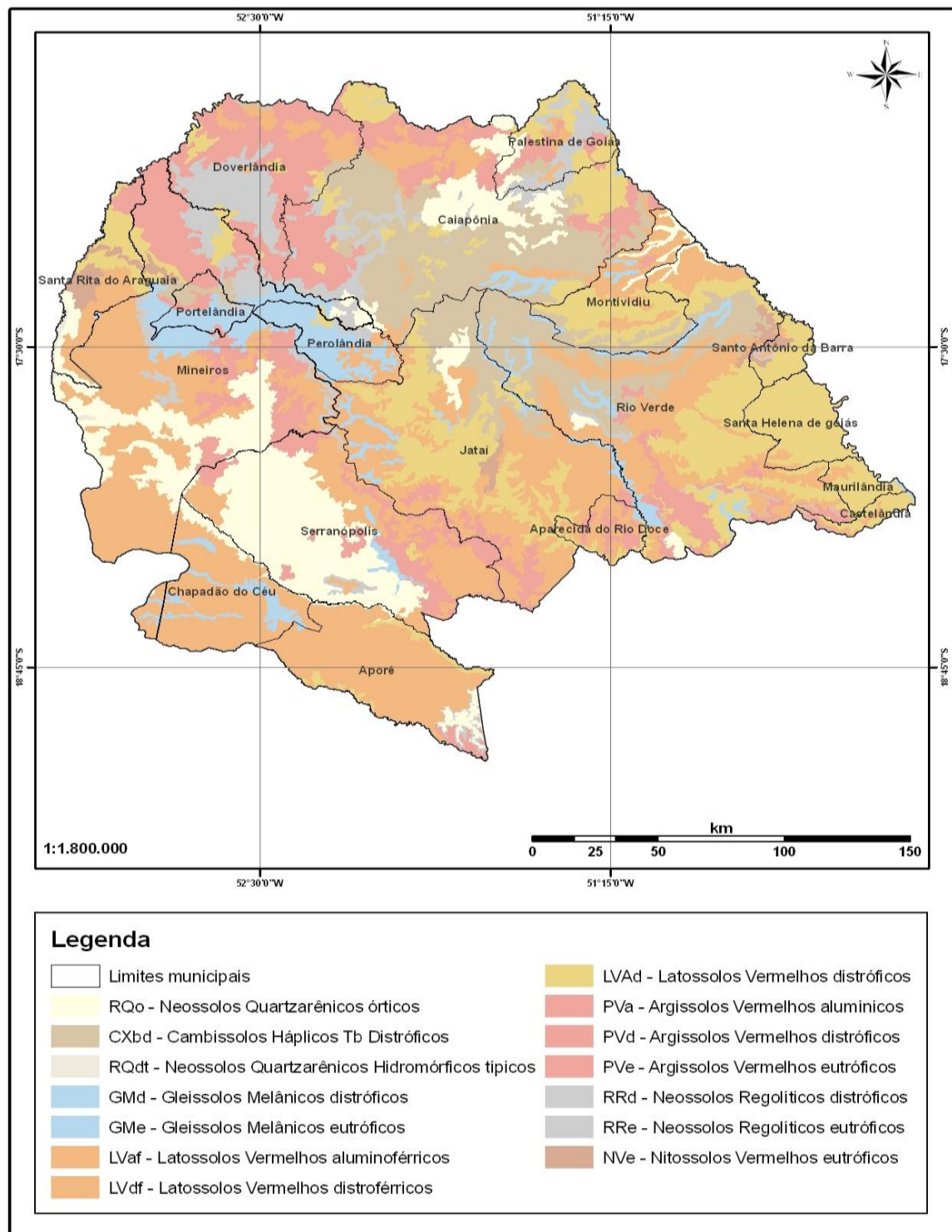

FIGURA 02: Unidades de mapeamento de solos identificadas no sudoeste de Goiás (BR). Fonte: SIEG (2006); RADAMBRASIL (1983). 
O Sistema de Avaliação da aptidão Agrícola das Terras (1995) considera que os solos com aptidão regular para lavouras e, dependendo da situação, até os considerados restritos, quando bem manejados, podem ser muito produtivos, apesar de requererem, nesses casos, maior investimento (PRADO, 2005).

De modo geral, no SW-GO, os melhores solos para lavouras anuais são os Latossolos, os Argissolos e os Nitossolos. Já os solos pouco profundos ou com limitações de drenagem, como os Cambissolos e os Gleissolos (hidromórficos), não são indicados para alguns tipos de cultivo, devido às limitações quanto ao desenvolvimento radicular, por causa da profundidade útil.

Assim, os solos com melhor aptidão agrícola ao cultivo da cana-de-açúcar estão situados onde a produção de grãos é a atividade predominante. Estes solos estão na porção leste e central da microrregião, locais dos maiores municípios, como Jataí e Rio Verde. Consequentemente, aí se encontra, também, a melhor logística de transportes como as rodovias BR 060, BR 158 e a BR 364 que ligam o Sudoeste à capital do Estado e às outras grandes cidades do Brasil (MIZIARA, 2009).

Além destes fatores atrativos, outros, como a legislação ambiental estadual sobre queimadas de canaviais (Lei $n^{\circ} 15.834$ de 23/11/2006), favorecem a instalação do setor sucroenergético em Goiás quando dispõe sobre a redução gradativa da queima da palha de cana-de-açúcar em áreas mecanizáveis no Estado de Goiás, prolongando o prazo em relação a São Paulo, por exemplo:

Art. 1 O Os plantadores de cana-de-açúcar que, utilizem como método de pré-colheita a queima da palha em áreas mecanizáveis, são obrigados a reduzirem gradativamente o uso do fogo com método despalhador e facilitador do corte, nos seguintes prazos e percentuais:

$1-1^{\circ}$ ao $5^{\circ}$ ano (2008-2012) - $10 \%$ da área cortada;

II $-6^{\circ}$ ao $10^{\circ}$ ano (2013-2017) - $25 \%$ da área cortada;

III $-11^{\circ}$ ao $15^{\circ}$ ano (2018-2022) - $50 \%$ da área cortada;

IV $-16^{\circ}$ ao $20^{\circ}$ ano (2023-2027) - $75 \%$ da área cortada;

$V-21^{\circ}$ ano (2028) -100\% da área cortada.

Art. 20 Para os efeitos desta Lei consideram-se áreas mecanizáveis as plantações em áreas acima de 150 ha (cento e cinquenta hectares), cujos terrenos sejam contíguos e apresentem declividade inferior a $12 \%$ (doze por cento), além de solos com estruturas que permitam a adoção de técnicas usuais de mecanização da atividade de corte de cana. ${ }^{5}$.

Outras vantagens incluem a fertilidade do solo, comparação feita entre áreas de agricultura e de pastagem, as quais implicam no tempo de vigência e nos valores pagos nos contratos de arrendamento, feito entre usina e proprietário de terra. Portanto, as usinas têm feito contratos diferenciados entre sojicultores e pecuaristas. É importante salientar que os preços das terras não são a única condição para escolha das áreas uma vez que a logística, que permite acesso físico, é muito importante.

5. Lei Estadual n 15.834 de 23/11/2006. 
Neste sentido, os custos de implantação dos canaviais são mais baixos em áreas de agricultura, comparadas às áreas de pastagem, fato que se reflete no maior valor pago aos sojicultores do que aos pecuaristas. Entre as áreas de agricultura, a diferença paga se baseia na distância da indústria; já nas áreas de pasto, além da distância, a qualidade pedológica torna-se parâmetro significativo nos valores a serem estipulados nos arrendamentos. $\mathrm{O}$ fator fertilidade do solo aparece nitidamente quando se compara os rendimentos médios dos canaviais cultivados em um ciclo de cinco anos, aonde o declínio médio em áreas de pastagem chega a ser $64 \%$ maior ao das áreas de agricultura.

Portanto, o custo de implantação da cana, também, se torna maior em áreas de pastagem do que em áreas de agricultura, devido às quantidades maiores de insumos para a correção do solo, necessárias para uma boa produtividade da cana nessas áreas (FELTRAN-BARBIERI, 2009).

Um estudo realizado por Nassar et al. (2008) mostrou que dos 103.795 ha convertidos em cana entre 2007 e 2008 nos Estados de Goiás, Mato Grosso e Mato Grosso do Sul, 61 \% ocorreram sobre lavouras. Dos cinco Estados analisados (Minas Gerais, Goiás, Paraná, Mato Grosso do Sul e Mato Grosso), todos substituíram, majoritariamente, áreas agrícolas, entre os anos de 2007 e 2008. Goiás apresenta-se como o segundo Estado com a maior porcentagem de áreas agrícolas - $70 \%$ - e de pastagens - 30\% -, no ano de 2007 , no qual a cana expandiu sua área em 85.560 ha.

Já no ano de 2008, Goiás se tornou, entre os Estados, nomeados anteriormente, o de maior porcentagem de substituição de áreas agrícolas, $76 \%$ contra $24 \%$ de pastos, em uma área cultivada com cana de 143.155 ha. Um segundo estudo, incluindo os Cerrados de Minas Gerais, São Paulo e oeste baiano, concluiu que na expansão canavieira entre 2004 e 2008, dos 270.735 ha, 50,4 \% ocorreu sobre lavouras, $33 \%$ sobre pastagens, 5,3 \% sobre vegetação nativa e 11,2 \% em cima de outros usos (RAMOS-NETO e FELTRAN-BARBIERI, 2009).

Fazendo-se uma análise apenas do Estado de São Paulo, a área total de agricultura e pastagem, substituídas até o ano-safra 2008/2009, foi, respectivamente, de 266.272 ha e de 374.180 ha. Portanto, a expansão das áreas de cana no Estado de São Paulo ocorreu mais em áreas de pastagem do que em áreas de uso agrícola (RUDORFF et al., 2010).

No Estado de Goiás, segundo Silva e Miziara (2010), é possível identificar duas situações contrastantes nas quais, na porção norte, a expansão se dá, predominantemente, sobre o Cerrado e na porção sul, em substituição às áreas agropecuárias. Percebe-se, em relação às áreas ocupadas com outras formas de uso que perdem lugar para o cultivo da cana-deaçúcar, que a agricultura aparece em primeiro lugar, com 14,4\%, seguida da área de Cerrado, com $7,7 \%$, matas - áreas de não cerrado -, situadas na porção sul do Estado, com $4,8 \%$ e, por fim, a pecuária com 3,7\%.

Considerando apenas as áreas onde o cultivo da cana foi efetivado, confirma-se a ideia da substituição de áreas de agricultura, em 2002, uma vez que 67 \% destas áreas, atualmente ocupadas por cana, eram antes destinadas à agricultura. Assim, em Goiás pode-se dividir em duas tendências espaciais a expansão: a do norte e a do sul.

Fazendo-se uma análise temporal dos usos e coberturas do solo em 2006, que se transformaram em canaviais em 2011, no sudoeste de Goiás (Tabela 02), aproximadamente, 165.000 hectares foram substituídos por cana-de-açúcar. Deste total, 16,5 \% era vegetação 
(mata, cerrado e campo/regeneração), 28,4 \% era pastagem e 55, 1 \% era agricultura. Portanto, a expansão da cultura da cana-de-açúcar prevaleceu em áreas de cultivo de grãos, principalmente, soja e milho, isto justificado pelos fatores atrativos citados anteriormente.

TABELA 02: Cobertura e uso do solo no ano de 2006 (em hectare), nas áreas substituídas por canade-açúcar, em 2011, nos municípios do sudoeste de Goiás.

\begin{tabular}{|c|c|c|c|c|c|c|}
\hline MUNICÍPIO & MATA & CERRADO & $\begin{array}{c}\text { CAMPO / } \\
\text { REGENERAÇÃO }\end{array}$ & AGRICULTURA & PASTAGEM & CANA \\
\hline Aporé & 106,6 & 240,8 & 592,4 & $3.219,4$ & $1.840,3$ & 1,7 \\
\hline Castelândia & 82,0 & 11,2 & 8,7 & 3,3 & - & $11.295,6$ \\
\hline Chapadão do Céu & - & 611,8 & 231,3 & $34.365,5$ & 852,9 & 186,7 \\
\hline Jataí & 88,7 & 365,6 & 172,4 & $9.045,4$ & $4.149,2$ & - \\
\hline Maurilândia & 166,6 & 7,4 & 6,1 & - & $2.345,4$ & $21.806,4$ \\
\hline Mineiros & $2.023,4$ & $7.416,5$ & $9.327,9$ & $12.728,2$ & $20.220,5$ & 34,3 \\
\hline Montividiu & - & - & - & $1.886,8$ & - & - \\
\hline Perolândia & 263,1 & 352,2 & 35,8 & $7.818,0$ & 1,7 & - \\
\hline Portelândia & 7,3 & 48,8 & 24,0 & 2,6 & 843,9 & - \\
\hline Rio Verde & 189,7 & 42,1 & 4,1 & $4.406,8$ & $2.816,3$ & $8.976,4$ \\
\hline Sta. Helena & 361,4 & 37,6 & - & $3.132,3$ & $3.292,0$ & $56.353,6$ \\
\hline Sta. Rita do Araguaia & 44,4 & $1.041,5$ & 820,7 & - & $1.087,6$ & . \\
\hline Sto. Antônio da Barra & 69,6 & 19,1 & 2,8 & $7.950,2$ & 2,3 & 1,7 \\
\hline Serranópolis & 85,5 & 395,5 & $1.819,3$ & $6.168,6$ & $9.262,6$ & - \\
\hline Total & $3.488,3$ & $10.590,1$ & $13.045,5$ & $90.727,1$ & $46.714,7$ & $98.656,4$ \\
\hline
\end{tabular}

O Zoneamento Agroecológico da Cana-de-açúcar no Brasil - ZAE - (MANZATTO, 2009), aprovado e regulamentado na forma de decreto № 6.961, de 17 de setembro de 2009 "incentiva" a expansão da cana-de-açúcar em áreas de "pastagens degradadas", ou seja, áreas que apresentem solos de baixa fertilidade natural e/ou o estabelecimento, formação e manejo da pastagem de maneira precária; condições estas, frequentemente, encontradas na pecuária extensiva no Estado. Dos municípios, que apresentaram valores expressivos de substituição de áreas de pastagem, sob Neossolos Quartzarênicos, e que, geralmente, são cultivados com pastagem degradada, Serranópolis possui $80 \%$ dos canaviais em Neossolos Quartzarênicos, Santa Rita do Araguaia, 46 \% e Mineiros $24 \%$.

Quanto às unidades de mapeamento de solos, a maior área com cana no ano de 2011 , no SW-GO, era a dos Latossolos com 186.811 ha; destes, 54,6 \% eram Latossolos Vermelhos Distroférricos e 22,2 \%, Latossolos Vermelhos Aluminoférricos. Os Neossolos Quartzarênicos apresentavam área cultivada com cana de 30.256 ha, correspondentes a 12,4\% das áreas de cana do SW-GO, no ano de 2011 (FRANCO, 2012).

Na Tabela 03 e na Figura 03 estão relacionadas às unidades de mapeamento de solos sob o cultivo de cana-de-açúcar nos municípios produtores de cana, no ano de 2011 no SW-GO, bem como, as áreas das unidades de mapeamento no município como um todo. 
TABELA 03: Áreas das Unidades de mapeamento de solos municipal e as ocupadas com canaviais (em hectare), em 2011, nos municípios da microrregião sudoeste de Goiás.

\begin{tabular}{|c|c|c|c|c|c|c|}
\hline \multirow{3}{*}{ MUNICÍPIO } & \multicolumn{6}{|c|}{ TIPO DE SOLO } \\
\hline & \multicolumn{2}{|c|}{ RQdt } & \multicolumn{2}{|c|}{ GMd } & \multicolumn{2}{|c|}{ GMe } \\
\hline & $\begin{array}{c}\text { Total } \\
\text { municipal }\end{array}$ & $\begin{array}{l}\text { Cana-de- } \\
\text { açúcar }\end{array}$ & $\begin{array}{c}\text { Total } \\
\text { municipal }\end{array}$ & $\begin{array}{l}\text { Cana-de- } \\
\text { açúcar }\end{array}$ & $\begin{array}{c}\text { Total } \\
\text { municipal }\end{array}$ & $\begin{array}{l}\text { Cana-de- } \\
\text { açúcar }\end{array}$ \\
\hline Aporé & - & - & 650,0 & 594,8 & - & - \\
\hline Castelândia & - & - & - & - & 740,1 & 259,3 \\
\hline Chapadão do Céu & - & - & $32.684,6$ & $3.262,8$ & - & - \\
\hline Jataí & - & - & $30.364,1$ & $1.269,3$ & $1.973,6$ & - \\
\hline Maurilândia & - & - & - & - & 920,7 & 38,8 \\
\hline Mineiros & $3.607,8$ & 338,1 & $68.347,0$ & $2.318,3$ & - & - \\
\hline Montividiu & - & - & $6.972,0$ & 541,1 & - & - \\
\hline Perolândia & - & - & $70.710,1$ & $7.297,4$ & - & - \\
\hline Portelândia & - & - & $27.864,6$ & 814,9 & - & - \\
\hline Rio Verde & - & - & $49.395,6$ & 265,4 & - & - \\
\hline Santa Helena & - & - & - & - & - & - \\
\hline Santa Rita do Araguaia & - & - & 652,5 & - & - & - \\
\hline Santo Antônio da Barra & - & - & - & - & - & - \\
\hline Serranópolis & - & - & $10.819,0$ & 539,9 & - & - \\
\hline Total & $3.607,8$ & 338,1 & $298.459,5$ & $16.903,9$ & $3.634,4$ & 298,1 \\
\hline
\end{tabular}

\begin{tabular}{|c|c|c|c|c|c|c|}
\hline \multirow{3}{*}{ MUNICÍPIO } & \multicolumn{6}{|c|}{ TIPO DE SOLO } \\
\hline & \multicolumn{2}{|c|}{ LVaf } & \multicolumn{2}{|c|}{ LVdf } & \multicolumn{2}{|c|}{ LVAd } \\
\hline & $\begin{array}{c}\text { Total } \\
\text { municipal }\end{array}$ & $\begin{array}{c}\text { Cana-de- } \\
\text { açúcar }\end{array}$ & $\begin{array}{c}\text { Total } \\
\text { municipal }\end{array}$ & $\begin{array}{c}\text { Cana-de- } \\
\text { açúcar }\end{array}$ & $\begin{array}{c}\text { Total } \\
\text { municipal }\end{array}$ & $\begin{array}{c}\text { Cana-de- } \\
\text { açúcar }\end{array}$ \\
\hline Aporé & $95.721,0$ & $4.447,0$ & $140.510,0$ & 896,9 & - & - \\
\hline Castelândia & - & - & $26.103,1$ & $11.152,3$ & - & - \\
\hline Chapadão do Céu & $120.660,8$ & $14.225,4$ & $63.698,3$ & $17.215,2$ & - & - \\
\hline Jataí & $174.429,3$ & $4.190,5$ & $140.474,4$ & $2.969,1$ & - & - \\
\hline Maurilândia & $5.371,2$ & $4.333,2$ & $32.331,6$ & $19.983,6$ & - & - \\
\hline Mineiros & $104.827,7$ & $19.543,9$ & $162.841,0$ & $15.114,9$ & $77.159,6$ & 207,9 \\
\hline Montividiu & - & - & $58.267,5$ & $1.341,7$ & - & - \\
\hline Perolândia & - & - & $23.051,3$ & $1.167,2$ & - & - \\
\hline Portelândia & - & - & 0,1 & - & - & - \\
\hline Rio Verde & $110.376,2$ & $5.055,6$ & $303.833,0$ & $9.726,4$ & - & - \\
\hline Santa Helena & $5.756,1$ & $1.898,5$ & $107.140,5$ & $61.373,9$ & - & - \\
\hline Santa Rita do Araguaia & $29.063,2$ & 151,0 & $47.554,9$ & $1.447,1$ & - & - \\
\hline Santo Antônio da Barra & - & - & $35.259,2$ & $7.859,7$ & - & - \\
\hline Serranópolis & $22.068,9$ & - & $126.265,7$ & $2.693,0$ & - & - \\
\hline Total & $668.274,4$ & $53.845,1$ & $1.267 .330,6$ & $152.941,0$ & $77.159,6$ & 207,9 \\
\hline
\end{tabular}




\begin{tabular}{|c|c|c|c|c|c|c|}
\hline \multirow{3}{*}{ MUNICÍPIO } & \multicolumn{6}{|c|}{ TIPO DE SOLO } \\
\hline & \multicolumn{2}{|c|}{ PVa } & \multicolumn{2}{|c|}{ PVd } & \multicolumn{2}{|c|}{ RRd } \\
\hline & $\begin{array}{c}\text { Total } \\
\text { municipal }\end{array}$ & $\begin{array}{l}\text { Cana-de- } \\
\text { açúcar }\end{array}$ & $\begin{array}{c}\text { Total } \\
\text { municipal }\end{array}$ & $\begin{array}{c}\text { Cana-de- } \\
\text { açúcar }\end{array}$ & $\begin{array}{c}\text { Total } \\
\text { municipal }\end{array}$ & $\begin{array}{l}\text { Cana-de- } \\
\text { açúcar }\end{array}$ \\
\hline Aporé & - & - & $9.639,0$ & - & $8.340,1$ & - \\
\hline Castelândia & - & - & - & - & 564,7 & - \\
\hline Chapadão do Céu & - & - & - & - & - & - \\
\hline Jataí & - & - & $45.964,9$ & - & 207,0 & - \\
\hline Maurilândia & - & - & - & - & - & - \\
\hline Mineiros & $69.949,4$ & 19,7 & $114.105,0$ & $1.257,0$ & $74.529,1$ & 137,8 \\
\hline Montividiu & - & & $2.281,8$ & - & - & - \\
\hline Perolândia & - & & 15,1 & - & $5.441,9$ & 9,5 \\
\hline Portelândia & $5.669,4$ & & $7.439,0$ & 0,9 & $3.929,3$ & 82,5 \\
\hline Rio Verde & - & & $74.939,0$ & 860,6 & $11.672,0$ & - \\
\hline Santa Helena & - & & - & - & - & - \\
\hline Santa Rita do Araguaia & $3.592,9$ & & $8.806,4$ & - & - & - \\
\hline Santo Antônio da Barra & - & - & - & - & $2.060,4$ & - \\
\hline Serranópolis & - & - & $82.014,6$ & - & $32.825,8$ & 207,6 \\
\hline Total & $79.211,7$ & 19,7 & $345.204,8$ & $2.118,5$ & $139.570,3$ & 437,4 \\
\hline
\end{tabular}

\begin{tabular}{|c|c|c|c|c|c|c|}
\hline \multirow{3}{*}{ MUNICÍPIO } & \multicolumn{6}{|c|}{ TIPO DE SOLO } \\
\hline & \multicolumn{2}{|c|}{ NVe } & \multirow{2}{*}{$\begin{array}{l}--- \\
--- \\
\end{array}$} & \multirow{2}{*}{$\begin{array}{l}--- \\
---\end{array}$} & \multirow{2}{*}{$\begin{array}{l}--- \\
--- \\
\end{array}$} & \multirow{2}{*}{$\begin{array}{l}--- \\
---\end{array}$} \\
\hline & $\begin{array}{c}\text { Total } \\
\text { municipal }\end{array}$ & $\begin{array}{c}\text { Cana-de- } \\
\text { açúcar }\end{array}$ & & & & \\
\hline Aporé & $17.017,0$ & - & --- & --- & --- & --- \\
\hline Castelândia & - & - & --- & -- & -- & --- \\
\hline Jataí & $214.179,0$ & - & --- & --- & --- & --- \\
\hline Maurilândia & - & - & --- & --- & --- & --- \\
\hline Mineiros & $5.712,3$ & - & -- & --- & --- & --- \\
\hline Montividiu & $73.998,0$ & - & --- & --- & --- & --- \\
\hline Santa Helena & - & - & --- & --- & --- & --- \\
\hline Santa Rita do Araguaia & $23.498,6$ & - & --- & -- & --- & --- \\
\hline Santo Antônio da Barra & $7.534,7$ & 199,0 & --- & -- & --- & --- \\
\hline Serranópolis & 217,4 & - & --- & --- & --- & --- \\
\hline Total & $390.621,7$ & 199,0 & $\cdots$ & $\cdots$ & $\cdots$ & $\cdots$ \\
\hline
\end{tabular}

RQo: Neossolo Quartzarênico órtico; CXbd: Cambissolo Háplico Tb distrófico; RQdt: Neossolo Quartzarênico Hidromórfico típico; GMd: Gleissolo Melânico Distrófico; GMe: Gleissolo Melânico Eutrófico; LVaf: Latossolo Vermelho Aluminoférrico; LVdf: Latossolo Vermelho Distroférrico; LVAd: Latossolo Vermelho-Amarelo Distrófico; PVa: Argissolo Vermelho Alumínico; PVd: Argissolo Vermelho Distrófico; RRd: Neossolo Regolítico Distrófico; NVe: Nitossolo Vermelho Eutrófico.

Fonte: INPE (2012); RADAMBRASIL (1983) e SIEG (2006)

Org.: Franco (2012) 


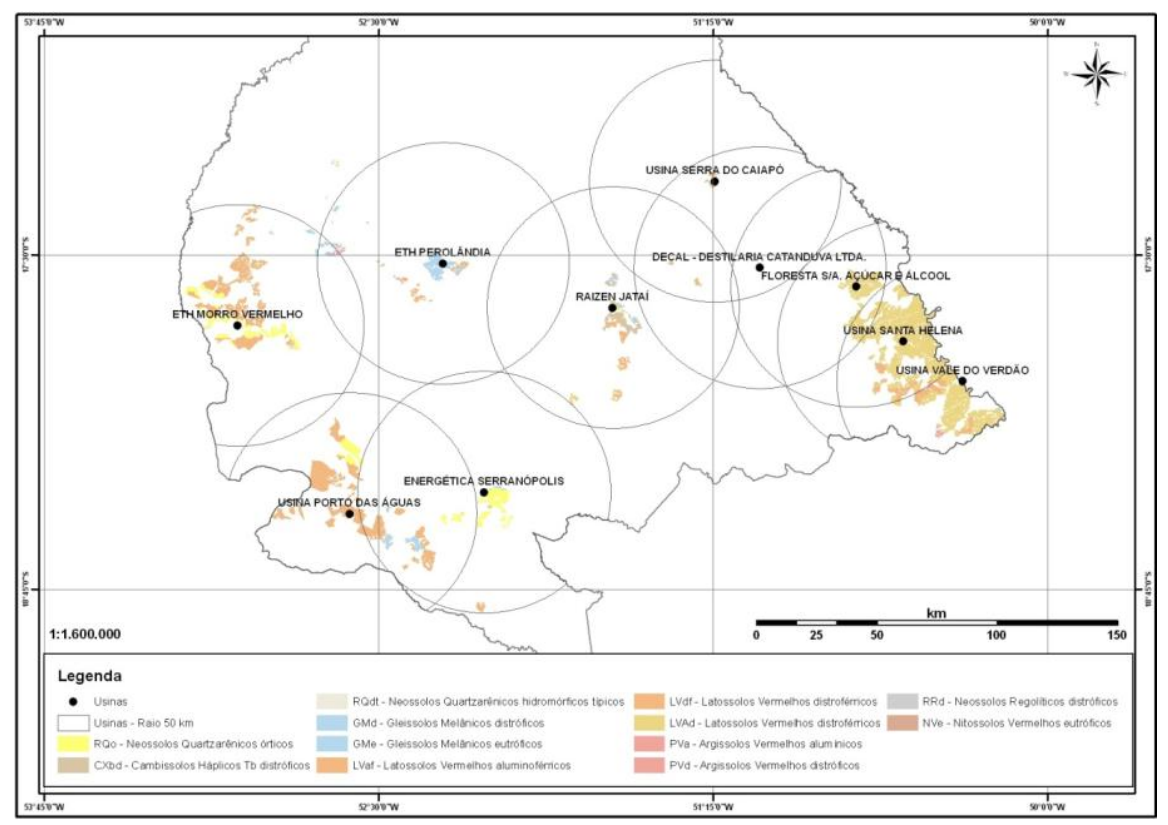

FIGURA 03: Áreas de cana-de-açúcar, no ano de 2011, sobrepostas às unidades de mapeamento de solos no sudoeste de Goiás.

Fonte: INPE (2012); RADAMBRASIL (1983) e SIEG (2006) / Org.: Franco (2012).

Na Figura 04, mostra-se um recorte ampliado de como foi feita a espacialização das unidades de mapeamento dos solos nos talhões de canaviais da Usina Centro-Oeste, grupo Raízen, localizados entre os municípios de Jataí e Rio Verde.

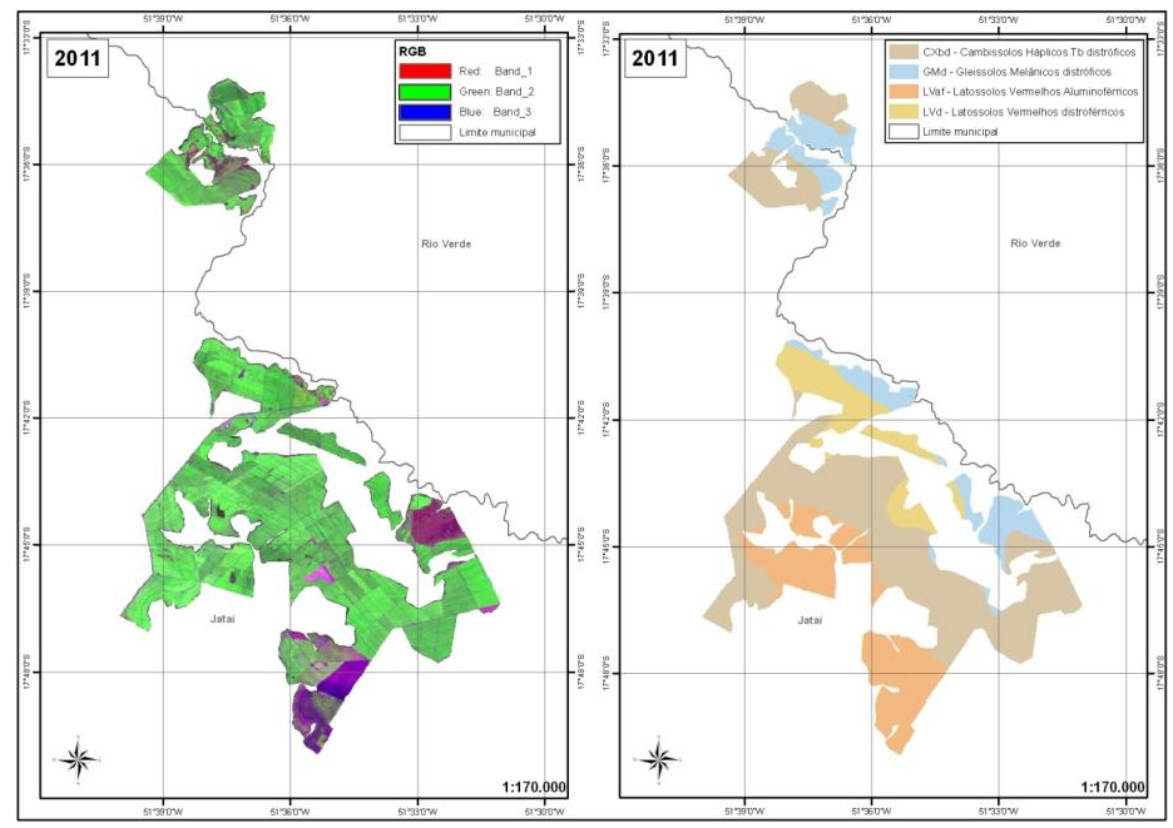

FIGURA 04: Mapa das unidades de mapeamento de solos nos talhões com canaviais, entre os municípios de Jataí e Rio Verde - recorte ampliado em uma área cultivada pela Usina Centro-Oeste, grupo Raízen.

Fonte: INPE (2012); RADAMBRASIL (1983) e SIEG (2006) / Org.: Franco (2012).

Para isto, utilizou-se a composição colorida do Landsat 5, bandas 5R4G3B. Observa-se que a área cultivada com cana está sobre Latossolos Vermelhos Distroférricos, Cambissolos e 
Gleissolos Melânicos, este último, distribuído próximo à divisa municipal, definida pelo Rio Doce.

De acordo com o mapa de solos, adaptado do SIEG (2006), em nível de ordem e subordem (às vezes, até grande grupo), as unidades de mapeamento de solos que ocorrem no SW_GO são as seguintes:

1) Neossolos Quartzarênicos - RQ;

2) Cambissolos Háplicos - CX;

3) Neossolos Quartzarênicos Hidromórficos - RQd;

4) Gleissolos Melânicos - GM;

5) Latossolos Vermelhos - LV;

6) Latossolos Vermelhos Distroférricos - LVd;

7) Latossolos Vermelho-Amarelos - LVA;

8) Argissolos Vermelhos - PV;

9) Neossolos Regolíticos - RR;

10) Nitossolos Vermelhos - NV.

A seguir, são descritas as duas principais classes (Latossolos e Neossolos Quartzarênicos) mapeadas no sudoeste de Goiás, quanto aos fatores limitantes ao uso agrícola.

\section{- Latossolos - L}

Os Latossolos são passíveis de utilização com culturas anuais, perenes, pastagens e reflorestamento. Normalmente, estão situados em relevo plano a suave-ondulado, com declividade que raramente ultrapassa 7\%, o que facilita a mecanização. São profundos, porosos, bem drenados, permeáveis, mesmo quando muito argilosos (EMBRAPA, 2006).

No Cerrado, a maioria dos Latossolos apresenta restrição agrícola devido à baixa fertilidade natural, associada à elevada acidez. Como respondem bem à calagem e à adubação e não apresentam limitações à mecanização, isto os torna excelentes solos para fins agrícolas no Cerrado (Figura 05). 


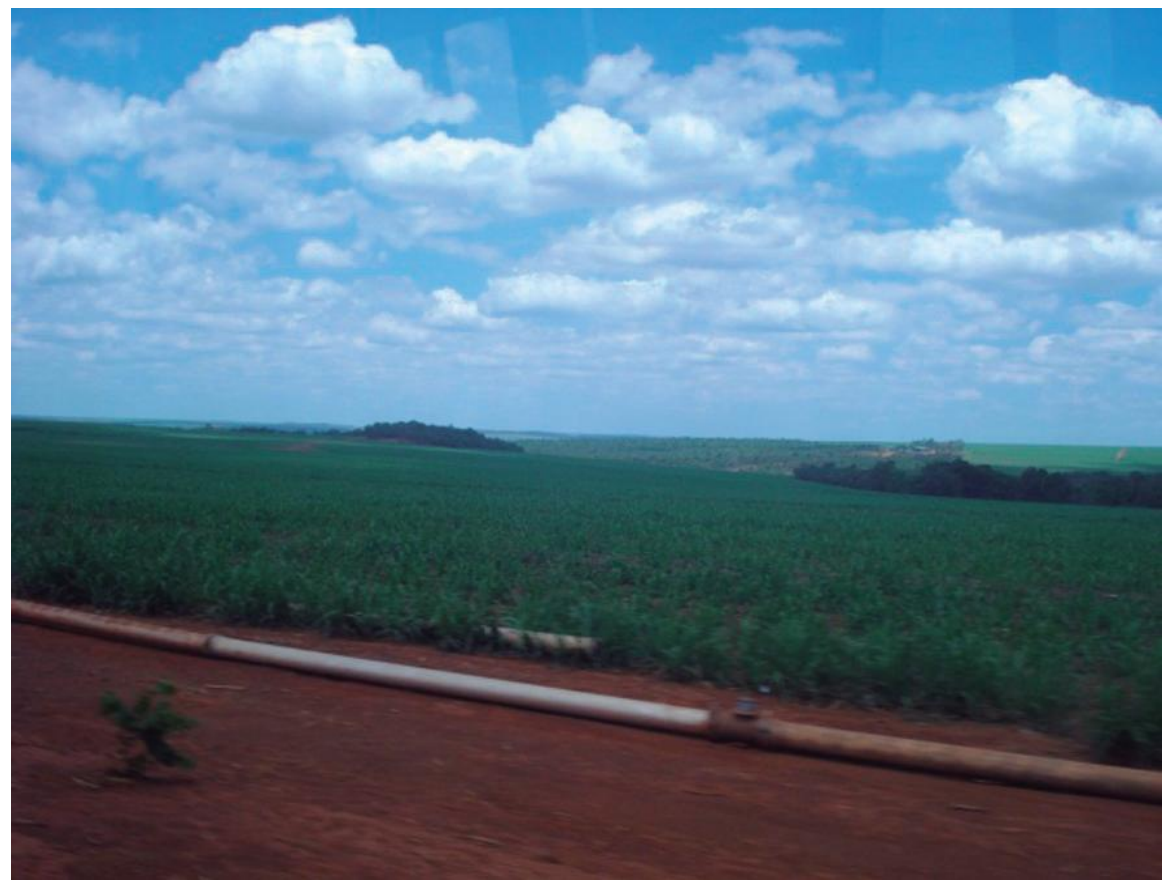

FIGURA 05: Canavial sob cultivo, em 2012, no município de Jataí, em Latossolo Vermelho Distroférrico, anteriormente era ocupado com soja e milho.

Fonte: Franco (2012).

\section{- Neossolos Quartzarênicos - RQ}

Os Neossolos Quartzarênicos são considerados solos com aptidão agrícola restrita ou inapta. O uso com culturas anuais exige um manejo muito específico e, na maioria das vezes, inviável. Práticas de manejo não adequadas determinam a sua degradação. A grande quantidade de areia, a quase inexistência de agentes de agregação, como a argila, os óxidos de ferro e alumínio e a matéria orgânica predispõem esses solos aos processos erosivos e, quando ocupam cabeceiras de drenagem, em geral, dão origem a voçorocas. Devido, também, à sua constituição textural e baixo teor em matéria orgânica, possuem muito baixa capacidade de armazenamento de água até $1 \mathrm{~m}$ de profundidade, fator considerado muito limitante para o cultivo de culturas anuais (SCOPEL et al., 2013).

Essas limitações ao uso agrícola sejam pela textura muito arenosa, fertilidade muito baixa ou, ainda, devido à toxidez de alumínio e à baixa capacidade de retenção de água, até pouca profundidade, dificuldades de mecanização, devido a isso, na microrregião sudoeste de Goiás, as áreas com $R Q$ são, mais frequentemente, usadas para pecuária ou, em tempos atuais (2010 e seguintes), algumas áreas estão sendo destinadas à cana-de-açúcar (Figura 06) ou ao reflorestamento com eucalipto. 


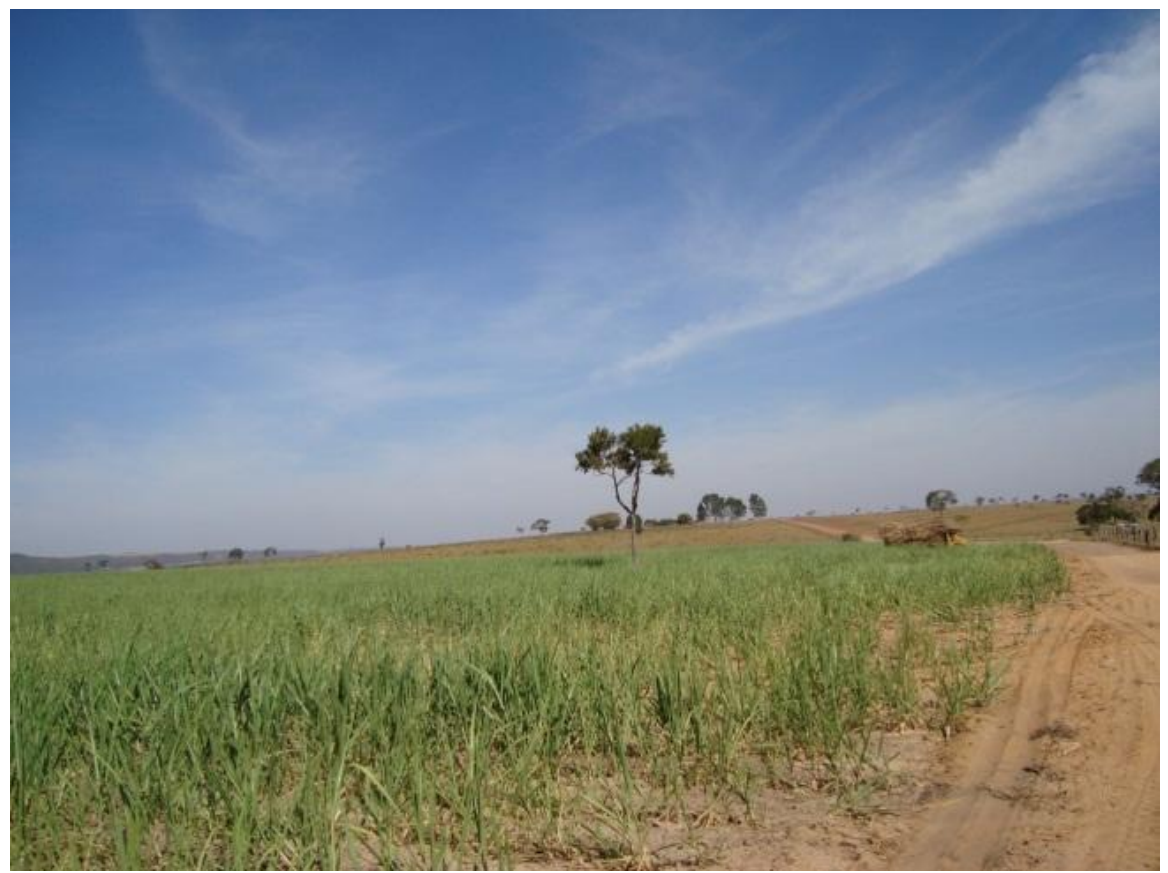

FIGURA 06: Neossolo Quartzarênico Órtico no município de Jataí - região da "Onça". Uso com canavial a partir de 2012 e, antes, com pastagem e pecuária.

Fonte: Franco (2012).

\section{CONCLUSÃO}

O mapeamento mostrou que a área cultivada com cana-de-açúcar no SW-GO é de 263.222 ha, equivalente a 33,2\% da área cultivada com cana em Goiás no ano-safra 2011/2012.

As unidades de mapeamento de solos com maior área sob cana-de-açúcar, no ano de 2011, no SW-GO eram a dos: Latossolos com 186.811 ha; destes, 54,6 \%, constituídos por Latossolos Vermelhos Distroférricos e 22,2 \% por Latossolos Vermelhos Aluminoférricos; os Neossolos Quartzarênicos apresentavam uma área cultivada com cana de 30.256 ha, o que correspondia a 12,4 \% das áreas de cana do SW-GO, no ano de 2011/2012.

Portanto, os Latossolos, passíveis de serem ocupados com diversas culturas anuais e alimentícias, ainda eram, em 2011, os preferidos para a atividade sucroenergética e é nesses solos que estava ocorrendo a maior expansão para exploração da cana-de-açúcar.

Além disso, o uso privilegiado dos Latossolos deveu-se, de modo geral, ao menor custo na exploração, ao menor risco climático e à maior facilidade nas práticas de manejo nesta classe de solos. Assim, a cana-de-açúcar destaca-se como muito tecnificada e onerosa, uma vez que o investimento para viabilizar o seu cultivo é 2,5 vezes maior do que aquele para a produção de soja, uma das atividades concorrentes em relação ao uso desses solos, no SWGO. Estes aspectos reforçam a preocupação quanto aos possíveis impactos que este cultivo pode trazer ao ambiente e ao solo, uma vez que os investimentos, no sistema capitalista, exigem retorno, às vezes, muito rápidos.

O uso desses solos - como os Latossolos, por exemplo - com potencial, ou que já estão sendo usados com outras culturas agrícolas, exige normativas sobre o interesse do país em ampliar neles as áreas com cana-de-açúcar, muito embora o discurso ambiental otimista, às 
vezes convincente, do setor sucroenergético no sentido de privilegiar a produção dessa cultura. Cabe lembrar, entretanto, que os estudos sobre os impactos ambientais e socioeconômicos, resultantes da implantação da cana-de-açúcar, ainda necessitam de muitas respostas.

\section{AGRADECIMENTOS}

Agradecimento especial à Universidade Federal de Goiás/Regional Jataí e aos órgãos de financiamento de pesquisa - CNPq/CAPES/FAPEG.

\section{BIBLIOGRAFIA}

ArcGis Imagine Software, versão 9.3. ESRI, 2007. Disponível em: ftp://ftp.puce.edu.ec/Facultades/CienciasExactas/Geoinformatica/MANUALES\%2OPARA\%20 LA\%20OPTATIVA/MANUALES\%20ARCGIS\%209.3/ArcGis\%20Manual\%209.3.pdf. Acesso em: jul. 2011.

CASTRO, S. S. de; BORGES, R. de O.; AMARAL, R. Estudo da expansão da cana-de açúcar no Estado de Goiás: subsídios para uma avaliação potencial de impactos ambientais. In: REUNIÃO ANUAL DA SBPC, 60., 2008, Campinas. Anais eletrônicos... São Paulo: SBPC/UNICAMP, 2008. Disponível em: http://www.sbpcnet.org.br/livro/60ra. Acesso em: jul. 2009.

COUTINHO, L. M. Aspectos do Cerrado. Vegetação. Estação Gráfica Ltda. São Paulo, 2000. Disponível em: http://eco.ib.usp.br/cerrado/aspectos vegetacao.htm. Acesso em: mar. 2012.

DEMATTÊ, J. L. I. Manejo e conservação de solos, na cultura da cana. Visão Agrícola. Piracicaba, jan./jun. 2004, p.8-17.

EMBRAPA SOLOS - Empresa Brasileira de Pesquisa Agropecuária. Sistema brasileiro de classificação de solos. $2^{\circ}$ ed. Rio de Janeiro: Embrapa Solos, 2009. 306p.

EMBRAPA SOLOS - Empresa Brasileira de Pesquisa Agropecuária. MAPA - Ministério da Agricultura Pecuária e Abastecimento. Zoneamento agroecológico da cana-de-açúcar. Org. Celso Vainer Manzatto... [et al.]. - Rio de Janeiro: Embrapa Solos, 2009. Disponível em: < http://www.planalto.gov.br/ccivil_03/_Ato2007-2010/2009/Decreto/D6961.htm> Acesso: fev. 2010.

ERDAS Imagine Software, versão 8.6. Atlanta, Georgia, Estados Unidos: Leica Geosistemas, 2002. Disponível em: http://web.pdx.edu/ emch/ip1/TourGuide86.pdf. Acesso em: jan. 2011.

GOIÁS (Estado). Gabinete Civil da Governadoria. Superintendência de Legislação. Disponível em: http://www.gabinetecivil.goias.gov.br/leis ordinarias/2006/lei 15834.htm. Acesso em: 13 jan. 2010.

FELTRAN-BARBIERI, R. Biocombustíveis, controvérsia agrícola na economia do petróleo: o caso do etanol no Cerrado. 2009. 231 f. Tese (Doutorado em Ciência Ambiental) - Programa de Pós-graduação em Ciência Ambiental da Universidade de São Paulo, São Paulo, 2009.

FRANCO, Í. O. Modelagem espacial da expansão canavieira no sudoeste de Goiás. 2012. 125 f. Dissertação (Mestrado em Geografia) - Programa de Pós-graduação em Geografia da Universidade Federal de Goiás, Jataí, 2012.

GUERRA, A. J. T.; PEREIRA, J. B. da S.; KASSAB, M. M.; FIGUEIREDO, P. R. H de; ALMEIDA, V. J.; REGIS, W. D. E. Um estudo do meio físico com fins de aplicação ao planejamento agrícola da 
terra do sudoeste de Goiás. Rio de Janeiro: IBGE, Departamento de Recursos Naturais e Estudos Ambientais, 1989. 212p.

IBGE - Instituto Brasileiro de Geografia e Estatística. Rio de Janeiro: IBGE, Sistema IBGE de Recuperação Automática - SIDRA. Produção Agrícola Municipal - PAM. Disponível em: http://www.sidra.ibge.gov.br/bda/acervo/acervo2.asp?e=v\&p=PA\&z=t\&o=11. Acesso em: mar. 2012.

INPE/CANASAT. Instituto Nacional de Pesquisas Espaciais. Monitoramento da Cana-deaçúcar via imagens de satélite. Disponível em: http://www.dsr.inpe.br/laf/canasat/tabelas.html>. Acesso em: mar. 2012.

KOFFLER, F.N.; DONZELI, P. L. Avaliação dos solos brasileiros para a cultura da cana-deaçúcar. In: PARANHOS, S. B. (Coord.). Cana-de-açúcar: cultivo e utilização. Campinas, Fundação Cargill. Cap. 1, 1987. p. 19-41.

LANDSAT TM 5: imagem de satélite. São José dos Campos: Instituto Nacional de Pesquisas Espaciais, 2011. Composição colorida 3, 4 e 5, RGB.

LEPSCH, I. F. Influência dos fatores edáficos na produção. In: CASTRO, P.R.C.; FERREIRA, S.O.; YAMADA, T. (Coord.) Ecofisiologia da produção. Piracicaba, Associação Brasileira para Pesquisa da Potassa e do Fosfato, 1987. p. 83-98.

LOPES, A. S. Solos sob "Cerrado": características, propriedades e manejo. $2^{\circ}$ ed. Piracicaba: Associação Brasileira para Pesquisa da Potassa e do Fosfato, 1984, p. 3-11.

MACEDO, J. Os solos da região dos Cerrados. In: ALVAREZ, V. H. et al. O solo nos grandes domínios morfoclimáticos do Brasil e o desenvolvimento sustentado. Viçosa: UFV, 1996, p. 135-155.

MALHEIROS, T. F.; HANAI, F. Y. Palestra proferida no Workshop sobre Avaliação Integrada de Sustentabilidade no contexto do Etanol. Universidade de São Paulo. Programa de Pósgraduação em Ciências da Engenharia Ambiental. São Carlos. 13 e 14 de abril de 2010.

MIZIARA, F. Expansão da Lavoura de Cana em Goiás e Impactos Ambientais. In: XIV CONGRESSO BRASILEIRO DE SOCIOLOGIA, 2009, Rio de Janeiro. Anais do XIV Congresso Brasileiro de Sociologia, v. 1, 2009.

NASSAR, A. M.; RUDORFF, L. B. A.; AGUIAR, D. A.; BACCHI, M. R. P.; ADAMI, M. Prospects of the sugarcane expansion in Brazil: impacts on direct and indirect land use changes. In: ZUURBIER, P. and VOOREN, J.V. (Edit) Sugarcane Ethanol: contributions to climate change mitigation and the environment. 1rst Ed. Wageniguen Publs. Wageninguen, 2008. p. 63-94.

PRADO, H. Ambientes de produção de cana-de-açúcar na região centro-sul do Brasil. In: POTAFÓS. ENCARTE DE INFORMAÇÕES AGRONÔMICAS, n.110, Piracicaba, 2005. p.12-17.

RADAMBRASIL. Levantamento de recursos naturais. Volume 31 folha se. 22 Goiânia, Goiás, Rio de Janeiro, 1983, $768 \mathrm{p}$.

RAMOS-NETO, M. B.; FELTRAN-BARBIERI, R. The truth about brazilian sugarcane etanol. Revista Biomass \& Bioenergy, jun. 2009.

RIBEIRO, J. F.; WALTER, B. M. T. As principais fitofisionomias do bioma Cerrado. Cap. VI IN: SANO, S. M.; ALMEIDA, S. P. \& RIBEIRO, J. F. Cerrado ecologia e flora. Embrapa Cerrado, Brasília - DF: Embrapa Informação Tecnológica, 2008. 406p.

RIZZO, L. T. B.; ORLANDO, F. J. Estimativa de distribuição da cultura de cana-de-açúcar nos solos do estado de São Paulo. Brasil Açucareiro, Rio de Janeiro, v.96, n. 5: 27-44, 1980.

RIBEIRO, N. V. Expansão sucroalcooleira no Bioma Cerrado: tendências, cenários e impactos. 2010. 84 f. Tese (Doutorado em Geografia) - Programa de Pós-graduação em Geografia da Universidade Federal de Goiás, Goiânia, 2010.

RUDORFF, B. F. T.; AGUIAR, D. A.; SILVA, W. F.; SUGAWARA, L. M.; ADAMI, M.; MOREIRA, M. A. Estudos sobre a rápida expansão da cana para produção de etanol no Estado de São Paulo 
(Brasil) utilizando dados do Landsat. Instituto Nacional de Pesquisas Espaciais (INPE), Divisão de Sensoriamento Remoto (DSR). São José dos Campos, São Paulo, Brasil. Publicado em: 09. abr. 2010.

SCOPEL, I et al. Análise das chuvas no centro-sul de Goiás. In.: CONGRESSO BRASILEIRO DE AGROMETEOROLOGIA, 2., Anais. Campina Grande/PB, 1995.

SCOPEL, I.; SOUSA, M.S.; MARTINS, A.P. Infiltração de água e potencial de uso de solos muito arenosos nos cerrados (savanas) do Brasil. Boletim Goiano de Geografia, Vol. 33, n. 2, Goiânia, 2013, p. 45 a 61.

SIEG - Sistema Estadual de Estatística e de Informações Geográficas de Goiás. Cobertura e Uso do Solo do Estado de Goiás do ano de 2006. Disponível em: http://www.sieg.go.gov.br. Acesso em: out. 2011.

SILVA, A. A.; MIZIARA, F. 2010. A expansão da fronteira agrícola e a localização das usinas de cana-de-açúcar. Pesquisa Agropecuária Tropical, UFG, Goiânia, v. 41, n. 3, pp. 399-407, jul./set., 2011.

Artigo submetido em

$02 / 02 / 2015$

Artigo aceito em

$06 / 09 / 2015$

